\title{
Syntheses, structures and luminescence behaviour of some zinc(II) complexes containing acetate and tetradentate Schiff bases
}

\author{
ASHIS KUMAR MAJI, SUBHASIS ROY, SOMNATH CHOUBEY, RAJARSHI GHOSH* and \\ BARINDRA KUMAR GHOSH* \\ Department of Chemistry, The University of Burdwan, Burdwan 713 104, India \\ e-mail: rajarshi_chem@yahoo.co.in; barin_1@yahoo.co.uk
}

MS received 11 October 2014; revised 10 January 2015; accepted 20 January 2015

\begin{abstract}
Two mononuclear compounds of the types pentacoordinated $[\mathrm{Zn}(\mathrm{L} 1)(\mathrm{OAc})] \mathrm{PF}_{6} \cdot \mathrm{H}_{2} \mathrm{O}(\mathbf{1})$ and hexacoordinated $[\mathrm{Zn}(\mathrm{L} 2)(\mathrm{OAc})] \mathrm{PF}_{6}(\mathbf{2})\left[\mathrm{L} 1=\mathrm{N}, \mathrm{N}^{\prime}\right.$-(bis(pyridin-2-yl)formylidene)-1,3-propanediamine; $\mathrm{L} 2=$ $\mathrm{N}, \mathrm{N}^{\prime}$-(bis(pyridin-2-yl)benzylidene)-1,4-butanediamine] have been synthesized using one-pot reactions of a 1:1:1 molar ratio of $\mathrm{Zn}(\mathrm{OAc})_{2} \cdot 2 \mathrm{H}_{2} \mathrm{O}, \mathrm{L} 1 / \mathrm{L} 2$, ammonium hexafluorophosphate in $\mathrm{MeOH}$ at room temperature. Compounds $\mathbf{1}$ and $\mathbf{2}$ are characterized on the basis of microanalytical, spectroscopic, thermal and other physicochemical results. Single crystal X-ray structural study reveals that the zinc(II) centre in $\mathbf{1}$ is coordinated by four $\mathrm{N}$ atoms of the Schiff base $\mathrm{L} 1$ and one $\mathrm{O}$ atom of terminal acetate with a $\mathrm{ZnN}_{4} \mathrm{O}$ chromophore, whereas in 2, the zinc(II) centre is bound by four $\mathrm{N}$ atoms of the tailored Schiff base L2 and two O atoms of the chelated acetate. In the crystalline state, mononuclear units in $\mathbf{1}$ are engaged in weak cooperative intermolecular O$\mathrm{H} \cdots \mathrm{O}$ and $\mathrm{C}-\mathrm{H} \cdots \mathrm{F}$ hydrogen bonds affording a $1 \mathrm{D}$ chain. The individual units of $\mathbf{2}$ are packed by $\pi \cdots \pi$ and anion $\cdots \pi$ interactions to form a $2 \mathrm{D}$ sheet structure. The complexes show reasonable thermal stabilities and display intraligand $\pi \rightarrow \pi^{*}$ fluorescence in solid state at room temperature.
\end{abstract}

Keywords. Mononuclear zinc(II); Schiff base; versatile acetate; X-ray structure; luminescence.

\section{Introduction}

The study of mono-, di-, and polynuclear complexes of zinc(II) has been the centre of current research because of their interesting synthetic, structural, spectroscopic and optoelectronic features ${ }^{1-4}$ and biological aspects. ${ }^{5}$ The essential prerequisites for such work are the judicious choice ${ }^{6}$ of organic spacers and inorganic/organic terminals/bridges that may lead to directed molecular properties. Recently, we got interested ${ }^{7-11}$ in the construction of different coordination molecules through variation of ligand backbones and metal ion coordination environments. In this regard, Schiff base spacers and pseudohalide terminals/bridges have been widely used. Schiff bases ${ }^{12,13}$ are useful chelators because of their ease of preparation, structural varieties, varied denticities and subtle steric and/or electronic control on their frameworks. Carboxylate like acetate is known to have different varieties of ligational motifs affording interesting molecular aggregates and crystalline architectures coupled with different physico-chemical properties. ${ }^{14-20}$ Earlier we reported ${ }^{16,18}$ some mono- and dinuclear copper(II) and nickel(II) acetate complexes in combination with a tailored diimine and a tailored Schiff base with interesting molecular and crystalline architectures coupled with ferromagnetic and luminescent properties. The present work stems from our interest to build new molecular and crystalline aggregates of zinc(II) acetates in combination with two Schiff bases viz. N, N'(bis(pyridin-2-yl)formylidene)-1,3-propanediamine (L1) and N, $\mathrm{N}^{\prime}$-(bis(pyridin-2-yl)benzylidene)-1,4-butanediamine (L2) (scheme 1). We have successfully isolated two mononuclear complexes $[\mathrm{Zn}(\mathrm{L} 1)(\mathrm{OAc})] \mathrm{PF}_{6} \cdot \mathrm{H}_{2} \mathrm{O}$ (1) and $[\mathrm{Zn}(\mathrm{L} 2)(\mathrm{OAc})] \mathrm{PF}_{6}(2)$. The details of synthesis, characterization, structure and properties of $\mathbf{1}$ and $\mathbf{2}$ are described below.

\section{Experimental}

\subsection{Materials}

High purity 1,3-propanediamine (Spectrochem, India), 1,4-butanediamine (Lancaster, UK), 2-benzoylpyridine (Lancaster, UK), zinc(II) acetate (E. Merck, India) and ammonium hexaflurophosphate (Fluka, Germany) were purchased from respective concerns and used as received. The Schiff base, N,N'-(bis(pyridin-2-yl)benzylidene)-1,3-propanediamine (L1)/N, $\mathrm{N}^{\prime}$-(bis(pyridin-2-yl) benzylidene)-1,4-butanediamine (L2) was prepared by condensation of 1:2 molar ratio of 1,3-propanediamine/ 1,4-butanediamine and 2-benzoylpyridine using the 


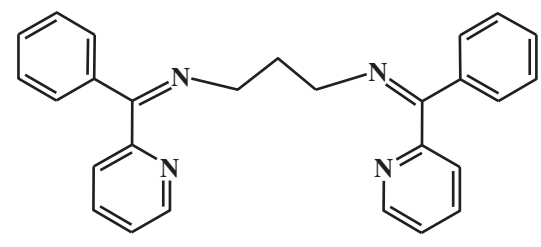

(L1)

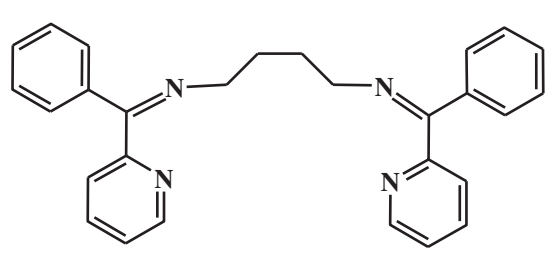

(L2)

Scheme 1. Frameworks of L1 and L2.

reported method. ${ }^{17,21}$ All other chemicals and solvents used were AR grade.

\subsection{Physical measurements}

Elemental analyses were performed on a Perkin-Elmer $2400 \mathrm{CHNS} / \mathrm{O}$ elemental analyzer. Molar conductance were measured using a Systronics conductivity meter where the cell constant was calibrated with $0.01(\mathrm{M})$ $\mathrm{KCl}$ solution, and dry $\mathrm{MeCN}$ was used as solvent. IR spectra (KBr discs, $4000-400 \mathrm{~cm}^{-1}$ ) were recorded using a Perkin-Elmer FTIR model RX1 spectrometer. Thermal behaviour were examined with a Perkin-Elmer Diamond TG/DT analyzer heated from $35-740^{\circ} \mathrm{C}$ under nitrogen. Ground state absorption spectra were measured with a Jasco model V-530 UV-Vis spectrophotometer. Solid state fluorescence measurements were done using a Hitachi Fluorescence Spectrofluorimeter F-4500.

\subsection{Isolation of the complexes [ $\mathrm{Zn}(\mathrm{L1})(\mathrm{OAc})]$ $\mathrm{PF}_{6} \cdot \mathrm{H}_{2} \mathrm{O}(\mathrm{1})$ and $[\mathrm{Zn}(\mathrm{L2})(\mathrm{OAc})] \mathrm{PF}_{6}$ (2)}

To a methanolic solution $(10 \mathrm{~mL})$ of $\mathrm{Zn}(\mathrm{OAc})_{2} \cdot 2 \mathrm{H}_{2} \mathrm{O}$ $(0.022 \mathrm{~g}, 0.1 \mathrm{mmol}), \mathrm{L} 1(0.04 \mathrm{~g}, 0.1 \mathrm{~mol})$ taken in the same solvent $(10 \mathrm{~mL})$ was added dropwise. To this resulting solution mixture, a methanolic solution $(5 \mathrm{~mL})$ of $\mathrm{NH}_{4} \mathrm{PF}_{6}(0.018 \mathrm{~g}, 0.1 \mathrm{mmol})$ was added as source of counter anion. The colourless reaction mixture was kept in an open air for slow evaporation. After a week colourless crystals of 1 were collected and dried in vacuo over silica gel indicator. Yield: $0.498 \mathrm{~g}$ (72\%). Complex 2 was prepared similarly using the same reaction stoichiometry and reaction condition as in $\mathbf{1}$ except that methanolic solution $(10 \mathrm{~mL})$ of L2 $(0.042 \mathrm{~g}, 0.1 \mathrm{mmol})$ instead of $\mathrm{L} 1$ was added to the reaction mixture. Yield: $0.516 \mathrm{~g} \mathrm{(75 \% ).} \mathrm{Anal.} \mathrm{Calc.} \mathrm{for} \mathrm{C}_{29} \mathrm{H}_{29} \mathrm{~N}_{4} \mathrm{O}_{3} \mathrm{~F}_{6} \mathrm{PZn}(\mathbf{1})$ : C, 50.3; H, 4.2; N, 8.1 Found: C, 50.1; H, 3.9; N, 8.3\%. IR $\left(\mathrm{KBr}, \mathrm{cm}^{-1}\right): v(\mathrm{O}-\mathrm{H}) 3422 ; v(\mathrm{C}=\mathrm{N}+\mathrm{C}=\mathrm{C}) 1633,1593$; $v_{\text {as }}\left(\mathrm{COO}^{-}\right) 1571 ; v_{\mathrm{s}}\left(\mathrm{COO}^{-}\right) 1334 ; v\left(\mathrm{PF}_{6}^{-}\right) 836,557$; UV-Vis [MeCN, $\left.\lambda_{\max } / \mathrm{nm}\left(\varepsilon, \mathrm{M}^{-1} \mathrm{~cm}^{-1}\right)\right]: 282\left(4.72 \times 10^{3}\right)$, $\Lambda_{\mathrm{M}}\left(\mathrm{MeCN}, \mathrm{ohm}^{-1} \mathrm{~cm}^{2} \mathrm{~mol}^{-1}\right): 115$. Anal. Calc. for $\mathrm{C}_{30} \mathrm{H}_{29} \mathrm{~N}_{4} \mathrm{O}_{2} \mathrm{~F}_{6} \mathrm{PZn}(2)$ : C, 52.3; H, 4.3; N, 8.1. Found:
$\mathrm{C}, 52.6 ; \mathrm{H}, 4.1 ; \mathrm{N}, 7.9 \% . \mathrm{IR}\left(\mathrm{KBr}, \mathrm{cm}^{-1}\right): v(\mathrm{C}=\mathrm{N}+\mathrm{C}=\mathrm{C})$ 1627,$1590 ; v_{\text {as }}\left(\mathrm{COO}^{-}\right) 1578 ; v_{\mathrm{s}}\left(\mathrm{COO}^{-}\right) 1329 ; v\left(\mathrm{PF}_{6}\right)$ 842, 557; UV-Vis [MeCN, $\left.\lambda_{\max } / \mathrm{nm}\left(\varepsilon, \mathrm{M}^{-1} \mathrm{~cm}^{-1}\right)\right]: 28$ $\left(17.04 \times 10^{3}\right), \Lambda_{\mathrm{M}}\left(\mathrm{MeCN}, \mathrm{ohm}^{-1} \mathrm{~cm}^{2} \mathrm{~mol}^{-1}\right): 110$.

\section{$2.4 X$-ray crystallographic analyses}

Single crystals of $\mathbf{1}$ and $\mathbf{2}$ suitable for X-ray analyses were selected from those obtained by slow evaporation of methanolic solutions at room temperature. Diffraction data were collected on a Bruker SMART CCD area-detector diffractometer using graphite monochromated Mo-K $\alpha$ radiation $(\lambda=0.71073 \AA$ ). Intensity data were reduced using SAINT ${ }^{22}$ and the empirical absorption corrections were performed with $\mathrm{SADABS}^{23}$ program. The structures were solved by SHELXS- $97^{24}$ and refined by full-matrix least-squares methods based on $|F|^{2}$ using the program SHELXL-97. ${ }^{24}$ All nonhydrogen atoms were refined with anisotropic displacement parameters whereas hydrogen atoms were located geometrically and refined using a standard riding model. Materials for publication were prepared using PLATON ${ }^{25}$ and Mercury $3.1^{26}$ programs. F8 atom of the hexafluorophosphate group in $\mathbf{1}$ is in disordered state with occupancy factors of $0.6 \%$ (F8A) and $0.4 \%$ (F8B). A summary of the crystallographic data and structure determination parameters for $\mathbf{1}$ and $\mathbf{2}$ is given in table 1 .

\section{Results and Discussion}

\subsection{Synthesis and formulations}

The penta- and hexacoordinated mononuclear compounds were isolated as single crystals through onepot synthesis of 1:1 molar ratio of zinc(II) acetate, tetradentate Schiff bases (L1/L2) and ammonium hexafluorophosphate in methanolic solution at room temperature. The new complexes were characterized using microanalytical (C, H and $\mathrm{N})$, spectroscopic, thermal and other physicochemical results. The microanalytical data are in good agreement with formulations $\mathbf{1}$ and $\mathbf{2}$. The moisture-insensitive complexes are stable over a long period of time and soluble in common organic 
Table 1. Crystal data and structure refinement for $\mathbf{1}$ and $\mathbf{2}$.

\begin{tabular}{|c|c|c|}
\hline Crystal parameters & 1 & 2 \\
\hline Empirical formula & $\mathrm{C}_{29} \mathrm{H}_{29} \mathrm{~N}_{4} \mathrm{O}_{3} \mathrm{~F}_{6} \mathrm{PZn}$ & $\mathrm{C}_{30} \mathrm{H}_{29} \mathrm{~N}_{4} \mathrm{O}_{2} \mathrm{~F}_{6} \mathrm{PZn}$ \\
\hline Formula weight & 691.89 & 687.91 \\
\hline Crystal system & Orthorhombic & Monoclinic \\
\hline Space group & Pbca & $\mathrm{P} 21 / \mathrm{n}$ \\
\hline$a(\AA)$ & $15.1451(3)$ & $9.6828(2)$ \\
\hline$b(\AA)$ & $15.1703(3)$ & $24.6511(6)$ \\
\hline$c(\AA)$ & $26.1615(5)$ & $13.6654(3)$ \\
\hline$\alpha\left(^{\circ}\right)$ & 90.00 & 90.00 \\
\hline$\beta\left(^{\circ}\right)$ & 90.00 & $110.501(2)$ \\
\hline$\gamma\left({ }^{\circ}\right)$ & 90.00 & 90.00 \\
\hline $\mathrm{V}\left(\AA^{3}\right)$ & $6010.8(2)$ & $3055.23(12)$ \\
\hline$\lambda(\AA)$ & 0.71073 & 0.71073 \\
\hline$\rho_{\text {calcd }}\left(\mathrm{g} \mathrm{cm}^{-3}\right)$ & 1.489 & 1.496 \\
\hline $\mathrm{Z}$ & 8 & 4 \\
\hline Crystal size $\left(\mathrm{mm}^{3}\right)$ & $0.20 \times 0.11 \times 0.06$ & $0.22 \times 0.08 \times 0.05$ \\
\hline Temperature $(\mathrm{K})$ & $296(2)$ & $296(2)$ \\
\hline$\mu\left(\mathrm{mm}^{-1}\right)$ & 0.941 & 0.928 \\
\hline$F(000)$ & 2752 & 1408 \\
\hline$\theta$ ranges $\left(^{\circ}\right)$ & 2.05 to 27.30 & 1.79 to 27.12 \\
\hline$h / k / l$ & $-19 / 19,-19 / 18,-33 / 33$ & $-12 / 12,-31 / 31,-17 / 17$ \\
\hline Reflections collected & 91278 & 39989 \\
\hline Independent reflections $\left(\mathrm{R}_{\text {int }}\right)$ & 6716 & 6703 \\
\hline Data/restraints/parameters & $6716 / 12 / 443$ & $6703 / 0 / 398$ \\
\hline Goodness-of-fit on $\mathrm{F}^{2}$ & 1.056 & 0.997 \\
\hline Final $\mathrm{R}$ indices $[I>2 \sigma(I)]$ & $\begin{array}{c}\mathrm{R}=0.0481 \text { and } \\
\mathrm{wR}=0.1391\end{array}$ & $\begin{array}{c}\mathrm{R}=0.0512 \text { and } \\
\mathrm{wR}=0.1336\end{array}$ \\
\hline $\mathrm{R}$ indices (all data) & $\begin{array}{c}\mathrm{R}=0.0865 \text { and } \\
\mathrm{wR}=0.1729\end{array}$ & $\begin{array}{c}\mathrm{R}=0.1211 \text { and } \\
\mathrm{wR}=0.1871\end{array}$ \\
\hline Largest diff. peak and hole $\left(\mathrm{e} \AA^{-3}\right)$ & 0.675 and -0.450 & 0.518 and -0.554 \\
\hline
\end{tabular}

Weighting scheme: $\mathrm{R}=\Sigma\|\mathrm{Fo}|-| \mathrm{Fc}\| / \Sigma|\mathrm{Fo}|, \mathrm{wR}=\left[\Sigma \mathrm{w}\left(\mathrm{F}_{\mathrm{o}}^{2}-\mathrm{F}_{\mathrm{c}}^{2}\right)^{2} / \Sigma \mathrm{w}\left(\mathrm{F}_{\mathrm{o}}^{2}\right)^{2}\right]^{1 / 2}$, calcd $\mathrm{w}$ $=1 /\left[\sigma^{2}\left(\mathrm{~F}_{\mathrm{o}}^{2}\right)+(\mathrm{xP})^{2}+\mathrm{yP}\right] ; \mathrm{x}=0.0903$ (for 1), 0.1000 (for 2) and $\mathrm{y}=2.9010$ (for 1), 0.0000 (for 2), where $\mathrm{P}=\left(\mathrm{F}_{\mathrm{o}}^{2}+2 \mathrm{~F}_{\mathrm{c}}^{2}\right) / 3$.

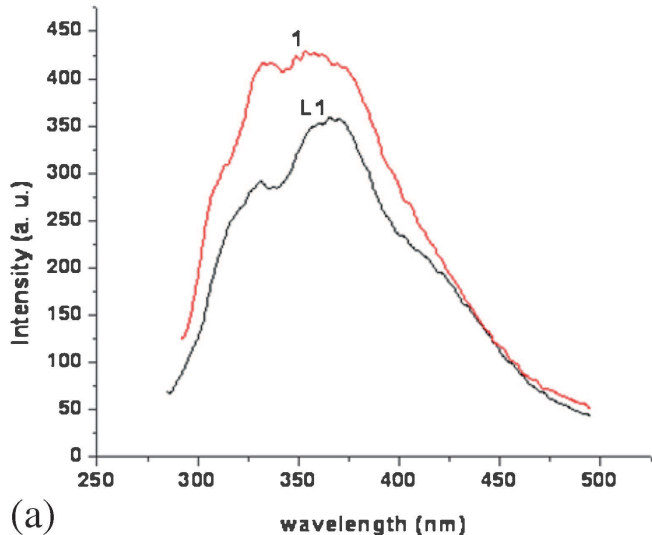

(a)

Figure 1. Fluorescence spectra of (a) L1 and 1; (b) L2 and 2 in MeCN solutions at room temperature.

solvents like $\mathrm{MeOH}, \mathrm{MeCN}, \mathrm{DMF}$ and DMSO, but are insoluble in water. In MeCN solutions, both the compounds show 1:1 electrolytic behaviour ${ }^{27}$ as reflected in their low $\Lambda_{\mathrm{M}}$ values $\left(\mathbf{1}: 115 \mathrm{ohm}^{-1} \mathrm{~cm}^{2} \mathrm{~mol}^{-1} ; \mathbf{2}: 110\right.$ $\mathrm{ohm}^{-1} \mathrm{~cm}^{2} \mathrm{~mol}^{-1}$ ).

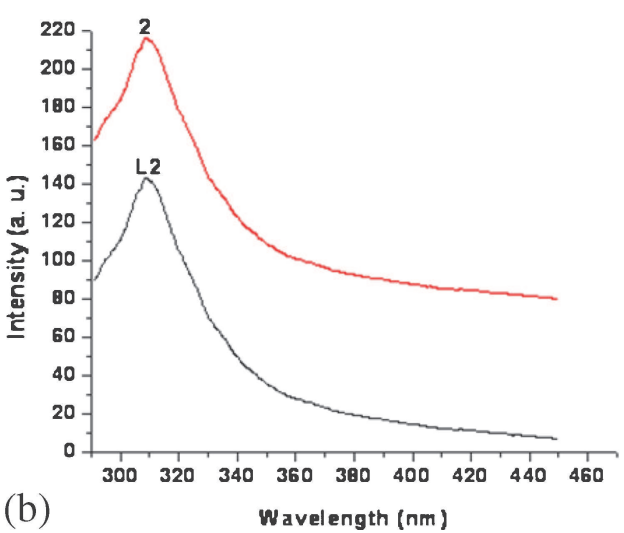

\subsection{Spectroscopic studies}

In IR spectra, Schiff bases L1 and L2 in the metal bound state exhibit $v(\mathrm{C}=\mathrm{N})$ plus $v(\mathrm{C}=\mathrm{C})$ stretching vibrations at $\sim 1630$ and $\sim 1590 \mathrm{~cm}^{-1}$. A strong absorption 


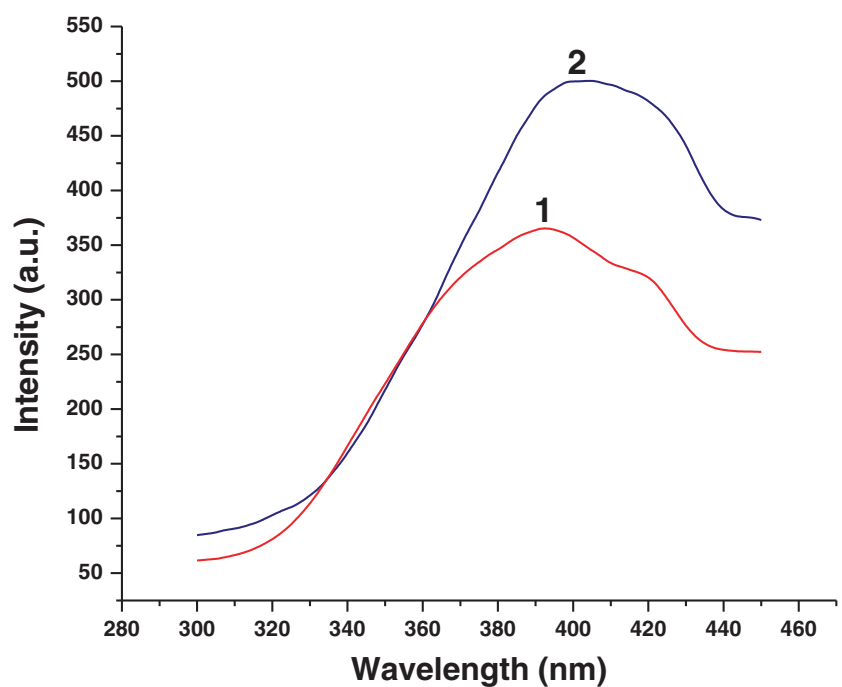

Figure 2. Solid state fluorescence spectra of $\mathbf{1}$ and $\mathbf{2}$ at room temperature.

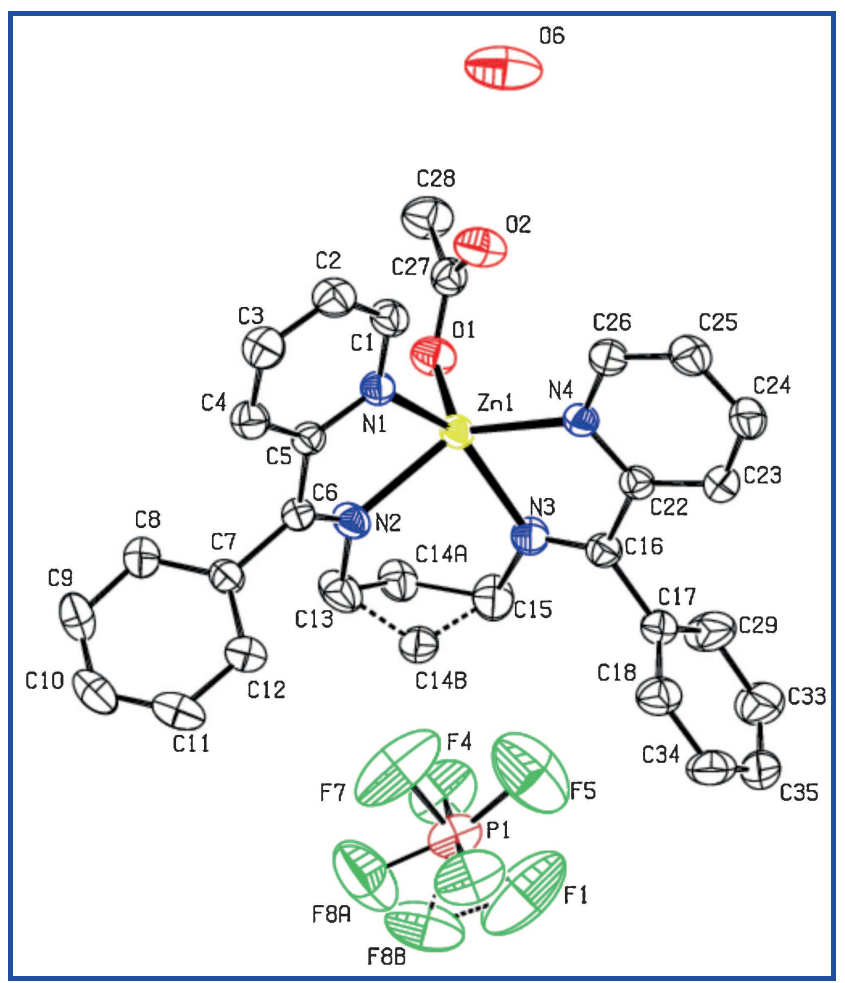

Figure 3. Molecular structure of $[\mathrm{Zn}(\mathrm{L} 1)(\mathrm{OAc})] \mathrm{PF}_{6} \cdot \mathrm{H}_{2} \mathrm{O}$ in $\mathbf{1}$ with atom numbering schemes.

at $3422 \mathrm{~cm}^{-1}$ for $v(\mathrm{O}-\mathrm{H})$ observed in case of $\mathbf{1}$ and absent in $\mathbf{2}$ strongly suggests the presence of water molecule in the former. The stretching frequencies $v_{\text {as }}$ $\left(\mathrm{COO}^{-}\right)$and $v_{\mathrm{s}}\left(\mathrm{COO}^{-}\right)$of acetate group are seen at $\sim 1570$ and $\sim 1330 \mathrm{~cm}^{-1}$, respectively. The presence of hexafluorophosphate at $\sim 840$ and $\sim 560 \mathrm{~cm}^{-1}$ indicates counter anionic view with no metal coordination. ${ }^{28}$ In MeCN solutions, complexes $\mathbf{1}$ and $\mathbf{2}$ show absorptions

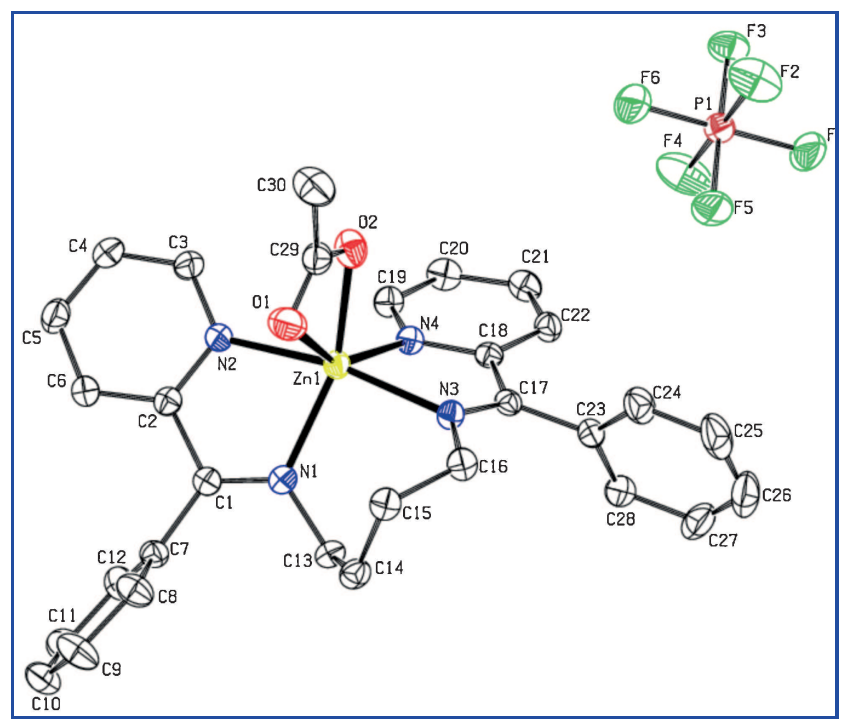

Figure 4. ORTEP of $[\mathrm{Zn}(\mathrm{L} 2)(\mathrm{OAc})] \mathrm{PF}_{6}(2)$ with atom numbering schemes.

Table 2. Selected bond distances $(\AA)$ for $\mathbf{1}$ and $\mathbf{2}$.

\begin{tabular}{lrlr}
\hline \multicolumn{2}{c}{ Bond distances for $\mathbf{1}$} & \multicolumn{2}{c}{ Bond distances for $\mathbf{2}$} \\
\hline Zn1-N1 & $2.143(3)$ & Zn1-N1 & $2.108(4)$ \\
Zn1-N2 & $2.137(3)$ & Zn1-N2 & $2.143(3)$ \\
Zn1-N3 & $2.160(3)$ & Zn1-N3 & $2.144(3)$ \\
Zn1-N4 & $2.117(3)$ & Zn1-N4 & $2.101(3)$ \\
Zn1-O1 & $1.953(3)$ & Zn1-O1 & $2.471(5)$ \\
C27-O1 & $1.266(5)$ & Zn1-O2 & $2.080(4)$ \\
C27-O2 & $1.225(5)$ & C29-O1 & $1.238(6)$ \\
& & C29-O2 & $1.250(6)$ \\
\hline
\end{tabular}

Table 3. Selected bond angles $\left({ }^{\circ}\right)$ for $\mathbf{1}$ and $\mathbf{2}$.

\begin{tabular}{lccc}
\hline \multicolumn{2}{c}{ Bond angles for $\mathbf{1}$} & \multicolumn{2}{c}{ Bond angles for $\mathbf{2}$} \\
\hline N1-Zn1-N2 & $76.46(10)$ & N1-Zn1-N2 & $77.52(13)$ \\
N1-Zn1-N3 & $147.36(12)$ & N1-Zn1-N3 & $92.03(13)$ \\
N1-Zn1-N4 & $99.79(10)$ & N1-Zn1-N4 & $112.35(13)$ \\
N2-Zn1-N3 & $85.18(11)$ & N2-Zn1-N3 & $168.69(14)$ \\
N2-Zn1-N4 & $138.12(11)$ & N2-Zn1-N4 & $101.83(13)$ \\
N3-Zn1-N4 & $76.27(10)$ & N3-Zn1-N4 & $77.97(13)$ \\
O1-Zn1-N1 & $107.43(11)$ & O1-Zn1-N1 & $98.48(13)$ \\
O1-Zn1-N2 & $104.18(12)$ & O1-Zn1-N2 & $87.79(14)$ \\
O1-Zn1-N3 & $103.08(12)$ & O1-Zn1-N3 & $98.14(13)$ \\
O1-Zn1-N4 & $116.37(11)$ & O1-Zn1-N4 & $148.97(13)$ \\
O1-C27-02 & $123.3(4)$ & O2-Zn1-N1 & $153.61(14)$ \\
& & O2-Zn1-N2 & $92.45(14)$ \\
& & O2-Zn1-N3 & $98.85(14)$ \\
& & O2-Zn1-N4 & $93.48(14)$ \\
& & O1-Zn1-O2 & $56.34(14)$ \\
& & O1-C29-02 & $122.0(5)$ \\
\hline
\end{tabular}

at 282 and $280 \mathrm{~nm}$, respectively assignable to ligandbased transition. ${ }^{29}$ The reflectance $[\mathbf{1}: \lambda, 280 \mathrm{~nm} ; \mathbf{2}: \lambda$, $278 \mathrm{~nm}$ ] in Nujol and electronic spectrum in $\mathrm{MeCN}$ for 
Table 4. Hydrogen bond distances $(\AA)$ and angles $\left(^{\circ}\right)$ for $\mathbf{1}$.

\begin{tabular}{|c|c|c|c|c|c|c|}
\hline Compound & D-H. . A & D-H & $\mathrm{H} \cdots \mathrm{A}$ & $\mathrm{D} \cdots \mathrm{A}$ & $\mathrm{D}-\mathrm{H} \cdots \mathrm{A}$ & Symmetry codes \\
\hline \multirow[t]{2}{*}{1} & O6-H119 ‥ O 2 & $0.85(8)$ & $1.97(9)$ & $2.815(6)$ & $170(9)$ & - \\
\hline & C14A-H14B $\cdots$ Fl & 0.9700 & 2.5200 & $3.248(9)$ & 131.00 & $1-x,-y, 1-z$ \\
\hline
\end{tabular}

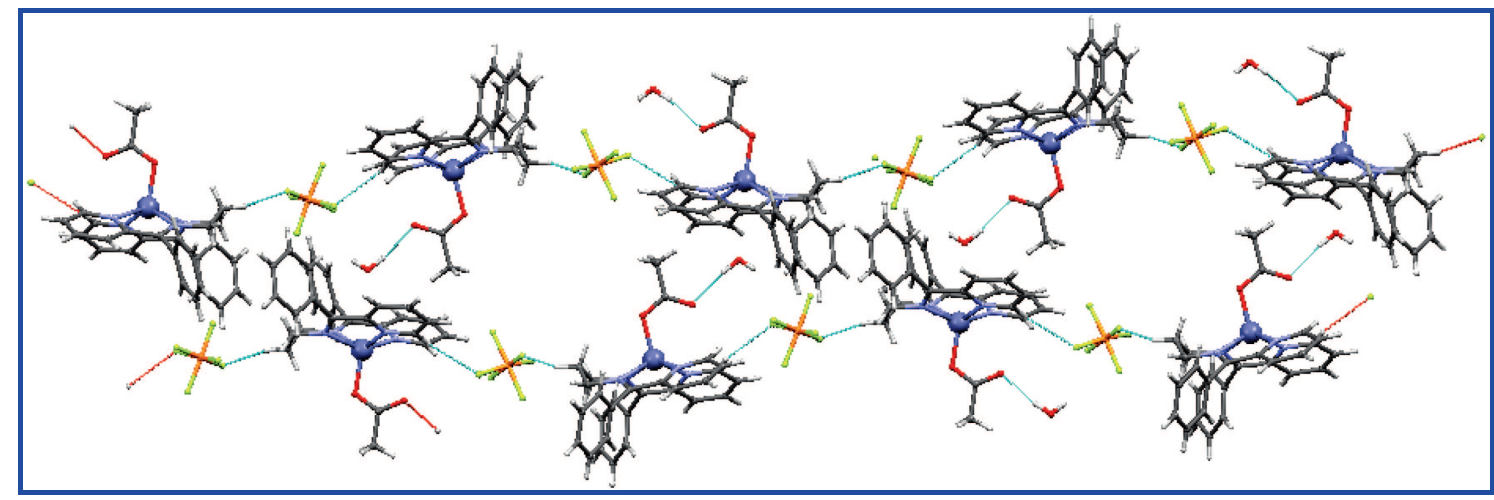

Figure 5. 1D chain structure in $\mathbf{1}$ formed through $\mathrm{O}-\mathrm{H} \cdots \mathrm{O}$ and $\mathrm{C}-\mathrm{H} \cdots \mathrm{F}$ hydrogen bonds along crystallographic $c$-axis.

Table 5. $\pi \cdots \pi$ Interaction parameter $\left(\AA,^{\circ}\right)$ for 2 .

\begin{tabular}{lccccc}
\hline $\mathrm{Cg}-\mathrm{Cg}$ & $\begin{array}{c}\mathrm{Cg}-\mathrm{Cg} \\
\text { distance }\end{array}$ & $\begin{array}{c}\text { Dihedral } \\
\text { angle }(i, j)\end{array}$ & $\begin{array}{c}\text { Perpendicular distances } \\
\text { between baricentres }(i, j)\end{array}$ & $\begin{array}{c}\text { Slippage } \\
\text { codes }\end{array}$ \\
\hline $\mathrm{Cg} 4 \cdots \mathrm{Cg} 4$ & $5.297(3)$ & 0.00 & $4.829(2)$ & 2.178 & $1-\mathrm{x}, 2-\mathrm{y}, 1-\mathrm{z}$ \\
$\mathrm{Cg} 4 \cdots \mathrm{Cg} 4$ & $4.567(3)$ & 0.00 & $3.893(2)$ & 2.389 & $2-\mathrm{x}, 2-\mathrm{y}, 1-\mathrm{z}$ \\
$\mathrm{Cg} 6 \cdots \mathrm{Cg} 6$ & $5.592(4)$ & 0.00 & $2.866(2)$ & 4.802 & $2-\mathrm{x}, 2-\mathrm{y}, 2-\mathrm{z}$ \\
\hline
\end{tabular}

Cg4: N(2)-C(2)-C(6)-C(5)-C(4)-C(3) and Cg6: C(7)-C(8)-C(9)-C(10)-C(11)-C(12)

Table 6. Anion $\cdots \pi$ interactions donor/acceptor scheme $\left(\AA,^{\circ}\right)$ for 2 .

\begin{tabular}{lccccc}
\hline $\mathrm{X}-\mathrm{D} \cdots \mathrm{A}$ & $\mathrm{X}-\mathrm{D}$ & $\mathrm{D} \cdots \mathrm{A}$ & $\mathrm{X} \cdots \mathrm{A}$ & $\mathrm{X}-\mathrm{D} \cdots \mathrm{A}$ & Symmetry code \\
\hline $\mathrm{P} 1-\mathrm{F} 6 \cdots \mathrm{Cg} 5$ & $1.562(3)$ & $3.414(4)$ & $4.459(2)$ & $122.9(2)$ & $-1 / 2+\mathrm{x}, 3 / 2-\mathrm{y},-1 / 2+\mathrm{z}$
\end{tabular}

Cg5: N(4)-C(18)-C(22)-C(21)-C(20)-C(19)

each complex are akin reflecting similar gross geometric structure and electronic structure in solid state and in solution. The photoluminescence behaviours of the ligands (L1 and L2) and the compounds $\mathbf{1}$ and $\mathbf{2}$ were examined in $\mathrm{MeCN}$ solutions and the compounds in the solid state at room temperature $(298 \mathrm{~K})$. As the Schiff base L1 was isolated in the form of a gummy mass, its fluorescence behaviour could not be measured in solid state. The spectral patterns are shown in figure 1. In $\mathrm{MeCN}$ solution, free L1 exhibits a broad fluorescent emission centred at $365 \mathrm{~nm}$ along with a weak emission at $330 \mathrm{~nm}$ (figure 1) upon excitation at the corresponding absorption band $(274 \mathrm{~nm})$. The corresponding compound 1 shows emission bands at the same wavelength with higher intensity when excited at $282 \mathrm{~nm}$. L2 shows emission at $310 \mathrm{~nm}$ upon photoexcitation at $278 \mathrm{~nm}$ in $\mathrm{MeCN}$ solution. Compound $\mathbf{2}$ shows emission bands at the same wavelength with higher intensity when excited at $280 \mathrm{~nm}$. Upon photoexcitation at the corresponding absorption band $280 \mathrm{~nm}$, solid sample of compound 1 containing L1 shows emission at $392 \mathrm{~nm}$ (figure 2). In our earlier study we have reported that L2 shows emission at $423 \mathrm{~nm}^{30}$ upon excitation at $280 \mathrm{~nm}$ in the solid state. Solid sample of compound $\mathbf{2}$ shows luminescence at $405 \mathrm{~nm}$ upon photoexcitation at $280 \mathrm{~nm}$. The luminescence in $\mathbf{1}$ and $\mathbf{2}$ in solid state as well as in $\mathrm{MeCN}$ solutions may be attributed to the intraligand $\left(\pi-\pi^{*}\right)$ emission..$^{10,11,31}$ 


\subsection{Molecular and crystalline structures of}

$[\mathrm{Zn}(\mathrm{L1})(\mathrm{OAc})] P \mathrm{~F}_{6} \cdot \mathrm{H}_{2} \mathrm{O}(\mathrm{1})$ and $[\mathrm{Zn}(\mathrm{L2})(\mathrm{OAc})] P F_{6}(2)$

ORTEP plots with atom numbering schemes of $\mathbf{1}$ and $\mathbf{2}$ are shown in figures 3 and 4, respectively. Selected bond lengths and angles pertaining to the coordination spheres of both the compounds are set in tables 2 and 3. Structural analysis reveals that the asymmetric unit in $\mathbf{1 / 2}$ consists of mononuclear species $[\mathrm{Zn}(\mathrm{L} 1 / \mathrm{L} 2)(\mathrm{OAc})] \mathrm{PF}_{6}$. $\mathrm{nH}_{2} \mathrm{O}$ [ $\mathrm{n}=1$ for $\mathbf{1}$ and $\mathrm{n}=0$ for 2] (figures 3 and 4 ) with or without lattice water. The coordination polyhedron around zinc(II) in $\mathbf{1}$ is best described as a distorted square pyramid $(\tau=0.15)^{32}$ with a $\mathrm{ZnN}_{4} \mathrm{O}$ chromophore whereas zinc(II) centre in $\mathbf{2}$ adopts a distorted octahedral geometry with a $\mathrm{ZnN}_{4} \mathrm{O}_{2}$ chromophore. Two pyridine $\mathrm{N}$ atoms ( $\mathrm{N} 1$ and $\mathrm{N} 4$ ) and two imine $\mathrm{N}$ atoms (N2 and N3) of the Schiff base (L1) complete the basal plane whereas the apical position is occupied by the $\mathrm{O} 1$

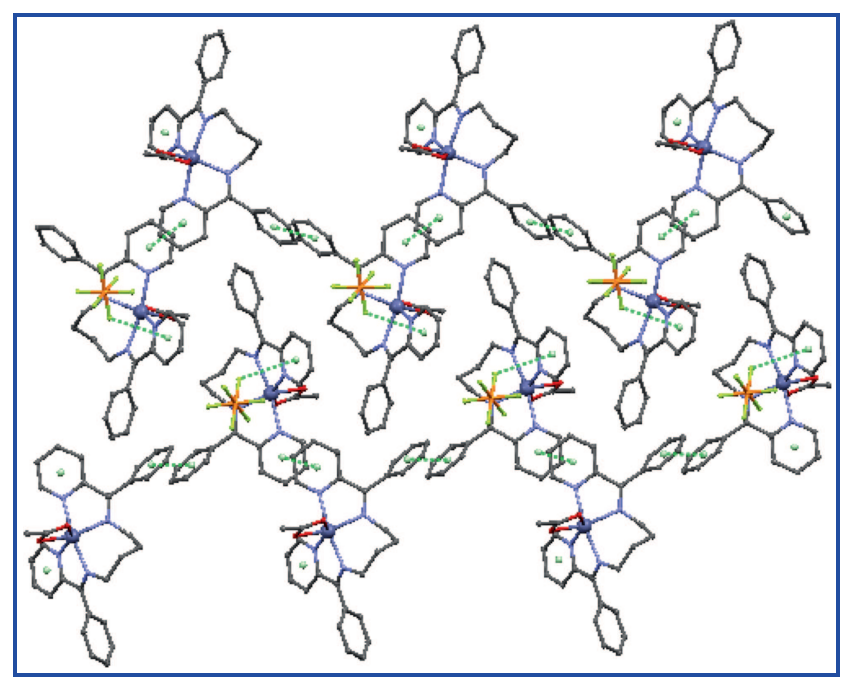

Figure 6. $2 \mathrm{D}$ sheet structure in 2 formed through $\pi \cdots \pi$ and anion $\cdots \pi$ interactions along crystallographic $a b$-plane. atom of the terminal acetate group (OAc). The core $\mathrm{Zn} 1$ atom is deviated by $0.67 \AA$ from the basal plane consisting of the four $\mathrm{N}$ atoms $(\mathrm{N} 1, \mathrm{~N} 2, \mathrm{~N} 3, \mathrm{~N} 4)$ of the Schiff base. The smaller $\mathrm{Zn}-\mathrm{O}(\mathrm{OAc})$ bond distance [1.953(3) $\AA$ ] in $\mathbf{1}$ over the average $\mathrm{Zn}-\mathrm{N}$ (Schiff base) distance $[2.139(8) \AA]$ is indicative of the stronger coordination of the anionic $\mathrm{O}$ atom of OAc over the neutral $\mathrm{N}$-atoms (N1 N2, N3 and N4) of the Schiff base. The propylenic arm of L1 is to some extent puckered and the central carbon atom of the arm is in a disordered state with occupancy factor of $0.75 \%(\mathrm{C} 14 \mathrm{~A})$ and $0.25 \%$ (C14B).

In the crystal structure of $\mathbf{2}$, two $\mathrm{O}$ atoms $(\mathrm{O} 1$ and $\mathrm{O} 2)$ of chelated acetate and one pyridine $\mathrm{N}$ atom (N4) and one imine N atom (N1) of the Schiff base (L2) occupy the equatorial positions while the remaining pyridine $\mathrm{N}(\mathrm{N} 2)$ and imine $\mathrm{N}(\mathrm{N} 3)$ atoms of L2 are placed at the axial positions. The distortion of the coordination spheres is reflected in the cisoid [56.34(14)-112.35(13) ${ }^{\circ}$ ] and the transoid [148.97(13)-168.69(14) $\left.{ }^{\circ}\right]$ angles. The metal centre is displaced from the mean equatorial plane by $0.011 \AA$. The average values of $\mathrm{Zn}-\mathrm{N}(\mathrm{L} 2)$ and $\mathrm{Zn}-\mathrm{O}(\mathrm{OAc})$ bond distances are $2.124 \AA$ and $2.275 \AA$, respectively. It is interesting to note that the $\mathrm{Zn}-\mathrm{O}$ distance in chelated form is so lengthened $(2.275 \AA)$ that it does not only overcome the $\mathrm{Zn}-\mathrm{O}$ bond distance [1.953(3) $\AA$ ] of terminal acetate in $\mathbf{1}$ but also the bond distance ( $2.124 \AA$ ) of $\mathrm{Zn}-\mathrm{N}($ Schiff base). The fourmembered chelate loop formed by this chelating carboxylate is a major factor for such enhancement. One four-membered chelate ring formed by the acetate and two five-membered and one seven-membered chelate rings formed by $\mathrm{L} 2$ surround the $\mathrm{Zn} 1$ centre. The tetradentate ligand is twisted around the zincl(II) centre such that the two planes containing the unsaturated chelate rings $(\mathrm{Zn} 1, \mathrm{~N} 3, \mathrm{C} 17, \mathrm{C} 18, \mathrm{~N} 4)$ and $(\mathrm{Zn} 1, \mathrm{~N} 1$,

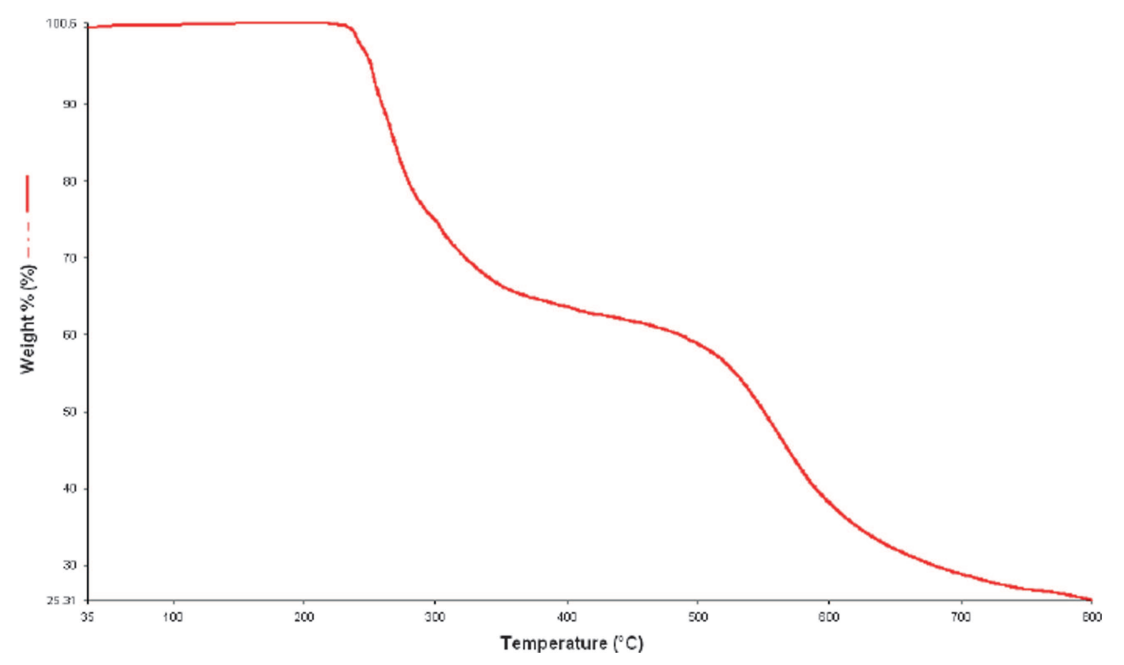

Figure 7. Thermal behaviour of $\mathbf{1}$. 


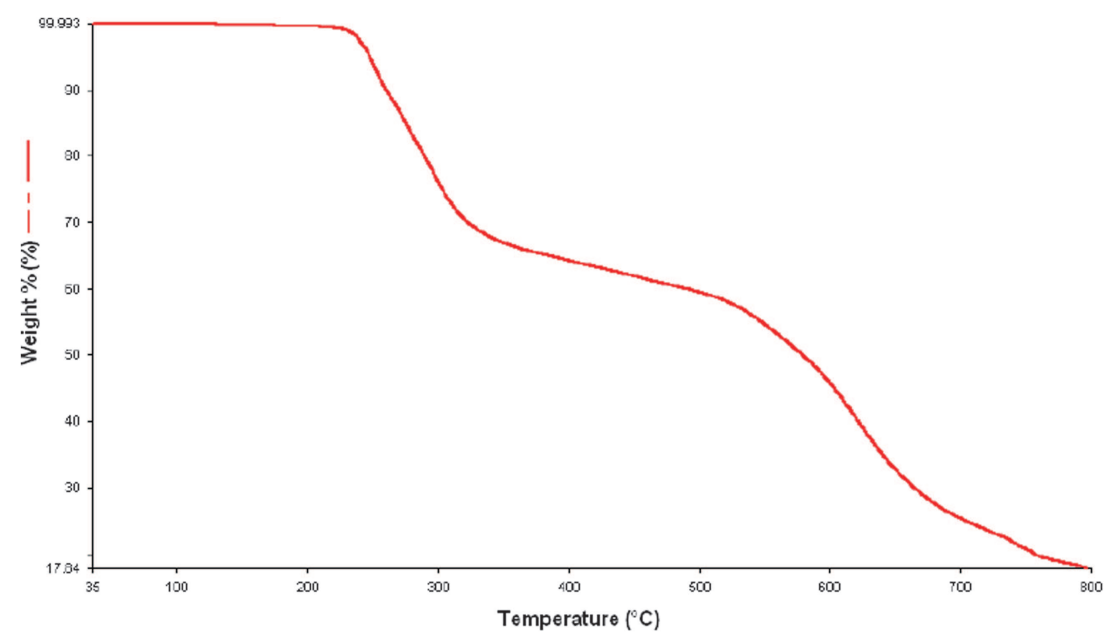

Figure 8. Thermal behaviour of 2 .

$\mathrm{C} 1, \mathrm{C} 2, \mathrm{~N} 2)$ are inclined at $61.12^{\circ}$ to each other. The butylenic arm of L2 is to some extent puckered.

In the crystalline state, mononuclear units in $\mathbf{1}$ are engaged in weak cooperative intermolecular $\mathrm{O}-\mathrm{H} \cdots \mathrm{O}$ hydrogen bonds (table 4) involving $\mathrm{O} 6$ and $\mathrm{H} 119$ atoms of crystalline water molecule and free $\mathrm{O} 2$ atom of acetate unit. Further, C-H...F hydrogen bonds involving $\mathrm{C} 14$ and $\mathrm{H} 14 \mathrm{~B}$ atoms of propylenic arm and neighbouring F1 atom of hexafluorophosphate unit lead to formation of a 1D chain (figure 5) along the crystallographic $c$-axis. In compound 2 anion $\cdots \pi$ interactions between F6 atom of hexafluorophosphate and neighbouring pyridine ring and $\pi \cdots \pi$ interactions involving two neighbouring pyridine rings (tables 5 and 6) give rise to a 2D sheet (figure 6) structure along the crystallographic $a b$-plane.

\subsection{Thermal study}

Thermogravimetric analyses of compounds $\mathbf{1}$ and $\mathbf{2}$ were carried out to examine their thermal stabilities. The crushed single crystals of $\mathbf{1}$ and $\mathbf{2}$ were heated between $40^{\circ} \mathrm{C}$ and $800^{\circ} \mathrm{C}$ temperature in the static atmosphere of dinitrogen at a heating rate of $10^{\circ} \mathrm{C} \mathrm{min}^{-1}$. The TG curve of $\mathbf{1}$ (figure 7) shows that compound $\mathbf{1}$ loses one water molecule (Obs.: 1.9\%, Calc.: 2.59\%) in the temperature range $106-241^{\circ} \mathrm{C}$. The next step in weight loss is associated with the removal of the acetate moiety and the Schiff base (Obs.: 72.8\%, Calc.: 66.8\%) in the temperature range $241-792^{\circ} \mathrm{C}$. On the other hand, compound $\mathbf{2}$ is devoid of water molecule and is stable up to $231^{\circ} \mathrm{C}$ (figure 8). The weight loss in $\mathbf{2}$ is in line with the removal of acetate group and the Schiff base (Obs.: 81.1\%, Calc.: 69.45\%) within the temperature range $231-797^{\circ} \mathrm{C}$.

\section{Conclusion}

In the present study, two zinc(II) acetate complexes in combination with two different tetradentate Schiff bases have been isolated and X-ray crystallographically characterized. A subtle change in coordination geometry from square pyramid to octahedral in going from $\mathbf{1}$ to $\mathbf{2}$ was observed with change of the end-capping ligands. In the crystalline state, different types of non-covalent forces in the complexes promote of dimensionalities with different crystalline architectures via cooperative $\mathrm{O}-\mathrm{H} \cdots \mathrm{O}$ and $\mathrm{C}-\mathrm{H} \cdots \mathrm{F}$ hydrogen bonds and anion $\cdots \pi$ and $\pi \cdots \pi$ interactions. The thermal behaviour shows that the frameworks in complexes $\mathbf{1}$ and $\mathbf{2}$ exhibit different stabilities. The compounds are examples of good luminous materials.

\section{Supplementary Information}

Crystallographic data for the structural analysis have been deposited with the Cambridge Crystallographic Data Center Nos. 1009238 (1) and 1009239 (2). Copies of this information can be had free of charge from. The Director, CCDC, 12 Union Road, Cambridge, CB2 1EZ, UK (fax: +44-1223-336033; e-mail: deposit@ ccdc.cam.ac.uk or http://www.ccdc.cam.ac.uk).

\section{Acknowledgements}

RG and BKG respectively thank the Department of Science and Technology (DST) and Council of Scientific and Industrial Research (CSIR), New Delhi, India for financial support. SC is grateful to CSIR and SR to UGC, New Delhi, India for fellowships. 


\section{References}

1. Huang W, Zhu H B and Gou S H 2006 Coord. Chem. Rev. 250414

2. Cavero E, Uriel S, Romero P, Serrano J L and Giménez R 2007 J. Am. Chem. Soc. 12911608

3. Jiang P and Guo Z 2004 Coord. Chem. Rev. 248205

4. Wang J, Lin Z, Ou Y C, Yang N L, Zhang Y H and Tong M L 2008 Inorg. Chem. 47190

5. (a) Prasad A S 1993 In Biochemistry of Zinc (New York: Plenum); (b) Eseola A O, Li W, Gao R, Zhang M, Hao $\mathrm{X}$ and Liang T 2009 Inorg. Chem. 489133

6. (a) Cook T R, Zheng Y R and Stang P J 2013 Chem. Rev. 113 734; (b) Lin Z J, Lu J, Hong M and Cao R 2014 Chem. Soc. Rev. 435867

7. Choubey S, Roy S, Bhar K, Mitra P, Ribas J and Ghosh B K 2014 Polyhedron 74134

8. Choubey S, Roy S, Bhar K, Ghosh R, Mitra P, Lin C H, Ribas J and Ghosh B K 2013 Polyhedron 551

9. Kundu S, Roy S, Choubey S, Bhar K, Ghosh P K, Mitra P and Ghosh B K 2013 J. Mol. Struct. 105141

10. Roy S, Sarkar B N, Bhar K, Satapathi S, Mitra P and Ghosh B K 2013 J. Mol. Struct. 1037160

11. Roy S, Choubey S, Bhar K, Khan S, Mitra P and Ghosh B K 2013 J. Mol. Struct. 1051328

12. Vigato P A and Tamburini S 2004 Coord. Chem. Rev. 2481717

13. Vigato P A, Peruzzo V and Tamburini S 2012 Coord. Chem. Rev. 256953

14. Massard A, Rogez G and Braunstein P 2014 Dalton Trans. $\mathbf{4 3} 42$

15. Langley S K, Helliwell M, Teat S J and Winpenny R E P 2014 Inorg. Chem. 531128

16. Chowdhury H, Rahaman S H, Ghosh R, Sarkar S K, Corbella M and Ghosh B K 2006 Inorg. Chem. Commun. 91276
17. Rahaman S H, Bose D, Ghosh R, Mostafa G, Fun H K and Ghosh B K 2007 Struct. Chem. 18237

18. Choubey S, Roy S, Khan S, Ghosh R, Bhar K and Ghosh B K 2013 J. Indian Chem. Soc. 90807

19. Ji Y -F, Wang R, Ding S, Du C -F and Liu Z -L 2012 Inorg. Chem. Comm. 1647

20. Orysyk S I, Bon V V, Obolentseva O O, Zborovskii Y L, Orysyk V V, Pekhnyo V I, Staninets V I and Vovk V M 2012 Inorg. Chim. Acta 382127

21. Bhar K, Khan S, Das S, Mitra P, Rosair G, Ribas J and Ghosh B K 2010 Inorg. Chim. Acta 363 3308

22. Sheldrick G M 1996 SAINT, V4: Software reference manual siemens analytical X-ray systems, Madison, WI, USA

23. Sheldrick G M 1996 SADABS: Program for empirical absorption correction of area detector data, University of Göttingen, Germany

24. Sheldrick G M 2008 Acta Crystallogr. A64 112

25. Spek A L 2009 Acta Crystallogr. D65 148

26. Macrae C F, Edgington P R, McCabe P, Pidcock E, Shields G P, Taylor R, Towler M and van de Streek J 2006 J. Appl. Crystallogr. 39453

27. Geary W J 1971 Coord. Chem. Rev. 781

28. Nakamoto K 2009 In Infrared and Raman spectra of inorganic and coordination compounds Part B, $6^{\text {th }}$ edition (New Jersey: John Wiley)

29. Lever A B P 1984 In Inorganic electronic spectroscopy, $2^{\text {nd }}$ edition (New York: Elsevier)

30. Sarkar B N, Roy S, Satapathi S, Ghosh R, Bhar K and Ghosh B K 2013 J. Indian Chem. Soc. 90943

31. Lakowicz J R 2006 In Principles of fluorescence spectroscopy $3^{\text {rd }}$ edition (USA: Springer)

32. Addision A W, Rao T N, Reedijik J, Rijn J V and Verschoor G C 1984 J. Chem. Soc. Dalton Trans. 1349 